PAPER

\title{
Personality change after stroke: some preliminary observations
}

\author{
J Stone, E Townend, J Kwan, K Haga, M S Dennis, M Sharpe
}

J Neurol Neurosurg Psychiatry 2004;75:1708-1713. doi: 10.1136/jnnp.2004.037887

See end of article for authors' affiliations

....................

Correspondence to: Dr J Stone, Department of Clinical Neurosciences, Western General Hospital, Edinburgh EH4 2XU, UK; jstone@skull.dcn.ed.ac.uk

Received 27 January 2004 Revised 20 February 2004 Accepted

20 February 2004
Objectives: To describe changes in personality after stroke and effects on carers.
Methods: A consecutive series of patients was recruited from hospital admissions with stroke. A novel questionnaire was administered to the patients' main carer at nine months after the stroke to determine their perception of the patients' pre-stroke and post-stroke personality. Personality change was identified by changes in these ratings, and associations between personality change and the following variables explored: emotional disorder in patients and carers (measured using the hospital anxiety and depression scale and a structured psychiatric interview), stroke classification (Oxford community stroke classification), residual disability (Barthel index and Nottingham extended activities of daily living scale), and lesion characteristics on computed tomography (CT).

Results: Carers of 35 patients with stroke took part. Reported changes in personality after stroke included: reduced patience and increased frustration (both $\mathrm{p}<0.0001, t$ test of difference), reduced confidence, more dissatisfaction, and a less easy going nature (all $p<0.005$ ). Occasionally, aspects of personality change were seen as positive by carers. There were relations between greater personality change and interviewer rated patient depression or anxiety $(p<0.001)$ but not when this was self rated; and between personality change and both emotional disorder in carers $(p<0.005)$ and greater disability $(p<0.01)$ but not CT lesion characteristics.

Conclusions: Carers commonly perceive personality change in stroke patients. This is associated with self rated emotional distress in the carer. More research is needed to understand what carers mean by "personality change" and what factors contribute to the perceived change.
“P ersonality change" is one of the most frequently voiced complaints of carers after their friend or relative has had a stroke. The overall clinical problem of personality change after stroke has received virtually no attention, ${ }^{1}$ although many of its likely constituents such as emotional disorder, cognitive impairment, and "brain injury" related changes in behaviour have been studied individually. ${ }^{2}$

In this preliminary study we had the following aims: to characterise change in personality as described by the carer across a wide range of descriptors; to test the hypotheses that perceived personality change is associated with depression and anxiety in patient and carer; and to seek associations between personality change, initial stroke severity, residual disability, stroke classification, and stroke lesion appearance on computed tomography (CT).

\section{METHODS}

\section{Patient recruitment}

Patients with stroke were recruited from a larger study of acute stroke care within a teaching hospital. Consecutive patients with a definite stroke were considered for inclusion by a stroke research fellow (JK) within the first few days after their stroke.

One month after the stroke, all patients except those with very severe stroke (that is, with a high chance of death), previously known dementia, or severe communication disorder were referred for further screening by a research psychologist (ET). After this screening, those patients who scored less than $8 / 10$ on an abbreviated mental test score, ${ }^{4}$ those who lived on their own, and those whose carer was unable to communicate with the researcher were excluded.

Nine months after the stroke, the patient and the carer who lived with the patient were approached to ask if they were willing to take part in the study. Patients with a previous stroke were included in the study, but for those patients it was made clear that we were interested in changes of personality specifically related to the most recent stroke. Patients were interviewed in their own home by the researcher (ET).

The study was approved by the local research ethics committee and all participants gave consent.

\section{Measures completed by carers}

We wished to explore personality change after stroke as observed by carers. In the absence of standardised measures to assess personality change in patients with neurological problems, we used a questionnaire incorporating items employed in studies of observer ratings of personality change after head injury - 20 items were taken from those used by Tyerman and Humphrey, ${ }^{5}$ augmented with additional items used by Brooks and McKinlay. ${ }^{6}$

Carers completed a standard questionnaire which required them to describe their relative's personality in terms of 30 descriptive adjectives (for example, bored, aggressive, caring). They did this on their own, while the patient was being interviewed, but could ask the researcher (ET) for help. For each adjective, they were asked to indicate how they saw their relative before the stroke and how they saw their

\footnotetext{
Abbreviations: DSM-IV, Diagnostic and Statistical Manual of Mental Disorders, 4th edition; EADL, extended activities of daily living scale; HAD, hospital anxiety and depression scale; LACS, lacunar stroke; OCSP, Oxford community stroke project classification; PACS, partial anterior circulation stroke; POCS, posterior circulation stroke; SCID, structured clinical interview for DSM-IV; TACS, total anterior circulation stroke
} 
relative now by responding "strongly disagree", "disagree", "neither agree nor disagree", "agree", "strongly agree". We chose this measure rather than standard personality questionnaires in order to capture changes relevant to brain damage in a way that could be readily understood and built on for future studies.

Carer emotional distress was measured by asking them to complete the hospital anxiety and depression (HAD) scale. This is a widely used scale measuring symptoms of anxiety and depression which has been validated in clinical and healthy populations. ${ }^{78}$

\section{Measures completed by patients}

On initial admission, the patient's stroke severity was recorded using the National Institute of Health stroke score (NIH score) ${ }^{9}$ and classified according to the Oxford community stroke project classification (OCSP). ${ }^{10}$ Computed tomography (CT) of the head was undertaken where possible as part of routine practice, usually within two days of stroke onset, and interpreted blind to reported personality change. Nine months after the stroke, at the same time as the carer ratings of personality change, residual disability was assessed with the Barthel index ${ }^{11}$ and the Nottingham extended activities of daily living scale (EADL). ${ }^{12}$ Emotional disorder in the patient was assessed with a structured clinical interview for the Diagnostic and Statistical Manual of Mental Disorders, fourth edition (DSM-IV) (SCID), which makes diagnoses according to the DSM-IV classification ${ }^{13}$ and with a continuous measure of distress, the self rated HAD scale. Antidepressant drug use at nine months was also recorded.

\section{Analysis}

We calculated a change score for each item by subtracting the pre-stroke rating from the post-stroke rating (where strongly agree $=0$, agree $=1$, neither agree nor disagree $=2$, disagree $=3$, and strongly disagree $=4$ ). We reverse scored 12 items (bored, unhappy, worried, frustrated, dissatisfied, irritable, unreasonable, quick tempered, aggressive, withdrawn, useless, worthless) which we judged to be negative personality characteristics. We then derived an overall personality change score by averaging all 30 change scores. For the purpose of seeking associations with CT lesion location data, we defined those patients with an overall mean change score of $>0.5$ as having "personality change".

The analysis was done in three stages. First, we described the carer ratings for each personality item pre- and poststroke, presenting mean scores and $95 \%$ confidence intervals (CI). The statistical significance of differences in pre- and post-stroke ratings were assessed using paired $t$ tests. Second, we explored the relation of patient age, stroke severity (NIH score), residual disability (Barthel, Nottingham EADL), patient emotional disorder (HAD, SCID), and carer emotional distress (HAD) with the overall personality change score using simple linear regression for each variable (categorical psychiatric data from the SCID interview were examined using unpaired $t$ tests). Finally, we examined the association of CT lesion location with the overall personality change score using the $\chi^{2}$ test for categorical data.

\section{RESULTS}

\section{Patient and carer characteristics}

We assessed 121 patients over a 13 month period. Figure 1 shows recruitment of cases and reasons for exclusion. The assessment was carried out a mean of 272 days (range 223 to 367) after the stroke. Eighty one patients were interviewed (fig 1).

After exclusions, there were 35 complete responses from patient and carer pairs available for analysis. Most exclusions were because the patient lived alone $(n=31)$ or because the
121 Consecutive inpatients with definite

stroke, able to communicate and without

obvious severe cognitive deficits

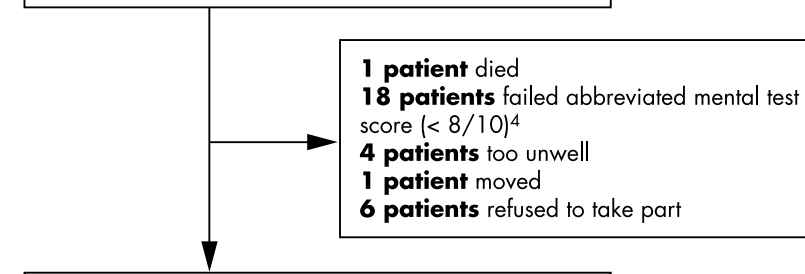

91 Patients approached for study at one month

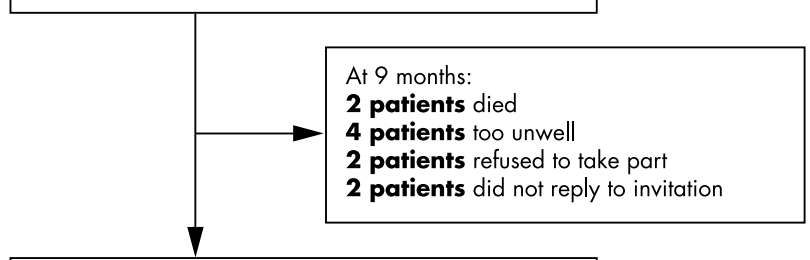

81 Patients enrolled in study at 9 months

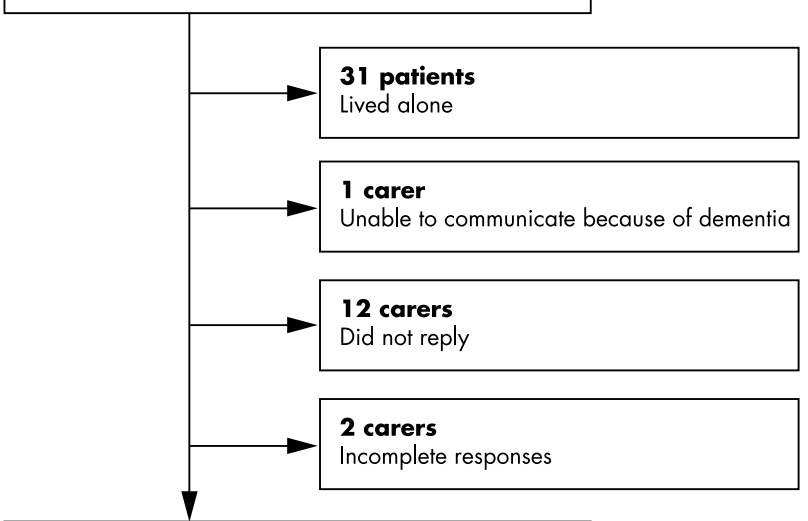

35 Patients and carer pairs completed study

Figure 1 Recruitment of cases and reasons for exclusion.

carer did not reply to the invitation to take part. The demographic characteristics, residual disability, and emotional disorder in patients who took part in the study and those who did not are shown in table 1. The sample studied was predominantly male $(68 \%)$ and the carers predominantly female $(68 \%)$. Stroke severity overall was relatively mild, with a median baseline NIH stroke score of 3 and a median Barthel score at 9 months of 19.

\section{Personality change}

Figures 2 and 3 show the carers' perceptions of their relative's personality before and nine months after their stroke, ordered according to the size of the perceived personality change. For clarity of presentation we have given positive and negative personality characteristics separately. There were significant differences between "before" and "after" ratings for over half the categories. These are indicated with asterisks on the figures.

We analysed each of the personality items according to whether the carer rated it as the same, more, or less after the stroke (table 2). This table emphasises that, while change in personality was usually perceived negatively, some carers reported a positive impact after stroke-for example, three carers reported that their relative had become less "unreasonable". 
Table 1 Patients and carers: clinical characteristics of participants and non-participants

\begin{tabular}{|c|c|c|c|}
\hline $\begin{array}{l}\text { Clinical characteristics of } \\
\text { patients and carers }\end{array}$ & Participating patients $(n=35$ ) & $\begin{array}{l}\text { Non-participating patients } \\
(n=54)^{*}\end{array}$ & Significance \\
\hline \multicolumn{4}{|l|}{ Patients } \\
\hline Sex of patients ( $\%$ male) & $69 \%$ male & $54 \% \mathrm{male}^{*}$ & NS (Fisher's exact) \\
\hline Median age of patients (range) & $\begin{array}{l}72 \text { (55 to } 91 \text { ) } \\
38 \% \text { visible infarct, } 50 \% \text { no visible infarct }\end{array}$ & 72 (range 33 to 90 )* & NS (Mann-Whitney) \\
\hline CT characteristics of lesion & $12.5 \%$ primary haemorrhage, $28 \%$ old infarct & - & - \\
\hline Side of lesion & $58 \%$ symptoms on left side of body & - & - \\
\hline NIH stroke score at admission & & & \\
\hline (median (range)) & $3.0(0$ to 21$)$ & 4.0 (range 0 to 21$)^{*}$ & NS (unpaired $t$ test) \\
\hline Oxford community stroke & TACS (4), PACS (10), LACS (14), & $\operatorname{TACS}(3), \operatorname{PACS}(13)$ & \\
\hline classification (n) & POCS (7) & $\operatorname{LACS}(21)$, POCS $(16)^{*}$ & NS $\left(\chi^{2}\right)$ \\
\hline $\begin{array}{l}\text { Average length of time between } \\
\text { stroke and assessment (range) }\end{array}$ & 272 days ( 223 to 367$)$ & NA & \\
\hline $\begin{array}{l}\text { Barthel index at } 9 \text { months } \\
\text { (median (range)) }\end{array}$ & $19(12$ to 20$)$ & 20 (7 to 20$)$ & NS (Mann-Whitney) \\
\hline $\begin{array}{l}\text { Nottingham EADL score at } 9 \text { months } \\
\text { (median (range)) }\end{array}$ & $17(2$ to 21$)$ & $17.5(2$ to 21$)$ & NS (Mann-Whitney) \\
\hline $\begin{array}{l}\text { Patient HAD score (mean scores) } \\
\text { Patient HAD score (\% with }\end{array}$ & Anxiety 4.8 ; depression 4.8 & Anxiety 4.7 ; depression 4.5 & NS (Mann-Whitney) $†$ \\
\hline significant score $(>7))$ & Anxiety $14 \%$; depression $14 \%$ & Anxiety $24 \%$; depression $20 \%$ & NS (Fisher's exact) $†$ \\
\hline \multicolumn{4}{|l|}{ Carers } \\
\hline Sex of carer (\% male) & $31 \%$ male & NA & NA \\
\hline Carer HAD score (mean scores) & Anxiety 7.9; depression 5.4 & NA & NA \\
\hline $\begin{array}{l}\text { Carer HAD score (\% with significant } \\
\text { score }(>7))\end{array}$ & Anxiety $51 \%$; depression $23 \%$ & NA & NA \\
\hline
\end{tabular}

*Includes all patients approached for the study at one month except two patients who died.

†Comparisons were for total HAD score.

CT, computed tomography; EADL, extended activities of daily living scale; HAD, hospital anxiety and depression scale; LACS, lacunar stroke; NA, not applicable; $\mathrm{NIH}$, National Institutes of Health; PACS, partial anterior circulation stroke; POCS, posterior circulation stroke; TACS, total anterior circulation stroke.

\section{Emotional disorder in patients and carers}

The structured clinical interview for DSM-IV, indicated that four patients ( $11 \%$ ) had a diagnosis of major depression, six (17\%) had minor depression, and six (17\%) had generalised anxiety disorder. Only one patient was taking an antidepressant drug (for sciatic nerve pain) and one other was taking minor tranquillisers for agoraphobia. On the HAD self rating scale, only $14 \%$ of the patients had scores for depression or anxiety of more than 7 . In contrast, $57 \%$ of the carers had HAD scores for depression or anxiety of more than 7 (51\% anxiety, 23\% depression).

\section{Associations between personality change and other variables \\ Emotional disorder in the patient}

The overall mean personality change score was used for these analyses. There was no association between personality change and total patient HAD score (simple linear regression, $r^{2}=0$ ). However, personality change was more likely to be reported in patients with an interviewer rated SCID diagnosis of major or minor depression (9/10 depressed patients $v 6 / 25$ non-depressed patients; $\mathrm{p}<0.01$, unpaired $t$ test) or generalised anxiety (4/5 anxious patients $v$ 11/25 non-anxious patients; $\mathrm{p}<0.01$, unpaired $t$ test).

\section{Emotional disorder in the carer}

Quick tempered

Withdrawn

Worthless

Aggressive

Useless

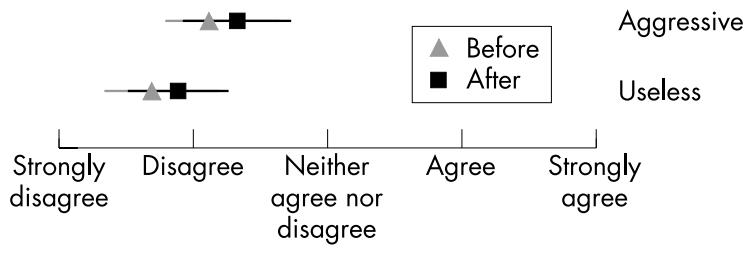

Figure 2 Carer's rating of patient personality pre- and post-stroke: negative personality characteristics. Lines represent $95 \%$ confidence intervals. ${ }^{*} p<0.05,{ }^{* *} p<0.005, t$ test.
The carer's rating of personality change in the patient was associated with total carer HAD score $\left(p<0.005, r^{2}=0.26\right.$, simple linear regression).

Residual disability, stroke severity, and stroke classification

There was an association between personality change and residual disability as measured by the Nottingham EADL scale $\left(\mathrm{p}<0.01, r^{2}=0.20\right)$ but not with the Barthel disability index. Greater personality change was also associated with the OCSP stroke classification $\left(\chi^{2}, p<0.05\right)$ (with the order of greatest to least change being: total anterior circulation stroke (TACS), posterior circulation stroke (POCS), partial anterior circulation stroke (PACS), and lacunar stroke (LACS) (table 3)). Greater personality change was not associated with baseline NIH stroke score or age. 


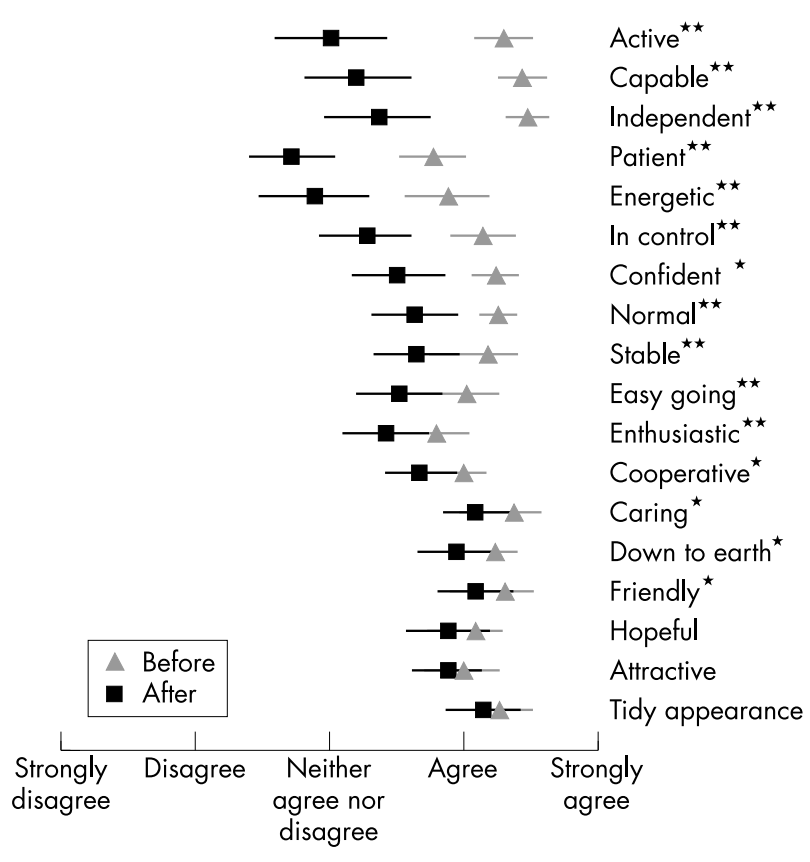

Figure 3 Carer's rating of patient personality pre- and post-stroke: positive personality characteristics. Lines represent $95 \%$ confidence intervals. ${ }^{*} p<0.05,{ }^{* *} p<0.005, t$ test.

\section{Stroke lesion characteristics}

Thirty two patients (91\%) had brain CT. This was done at a mean of 39 hours after stroke onset. Sixteen patients (52\%) had a visible infarct, 12 (39\%) had no visible infarct, and four (13\%) had evidence of a primary haemorrhage. In addition, 10 patients had evidence of an old infarct and one had suffered a previous primary haemorrhage. There was no statistically significant association between reported personality change, the presence of a visible infarct and laterality of the lesion, the proportion of patients with haemorrhage, cortical $v$ subcortical location, or grey matter $v$ white matter.

\section{DISCUSSION}

This preliminary study shows the variety of ways in which stroke can influence a carer's perception of a patient's personality. In our study there were significant negatively perceived changes in the carers' perception of characteristics such as frustration, dissatisfaction, unhappiness, worrying, patience, and being in control, energetic, confident, and easy going. However, for some patients, carers occasionally reported personality change in a positive direction-for example, reporting that their relative was less aggressive or less unreasonable.

The measure of personality change employed here was associated with interview rated but not self rated measures of emotional distress in the patient. We found an association between emotional distress in the carer and greater perceived personality change in the patient. Greater personality change was also associated with the Nottingham EADL but not with the Barthel score, both of which measure aspects of disability.

Personality change is a frequent and lasting complaint voiced by carers of stroke patients. Some aspects of this personality change-particularly those with more established biological substrates such as emotionalism ${ }^{2}$ and an inability to control anger ${ }^{314}$-are well described. In its totality, however, "personality change" as described by the carers appears to be a much broader phenomenon. It encompasses straightforward emotional disorder-changes in cognitive function, emotional expression, and behaviour probably as a
Table 2 Carers' rating of personality change according to whether the change was more, the same, or less for each feature

\begin{tabular}{llll}
\hline & More & The same & Less \\
\hline "Positive" personality characteristics & & \\
Patient & 1 & 12 & 22 \\
Capable & 0 & 14 & 21 \\
Active & 0 & 14 & 21 \\
In control & 1 & 14 & 20 \\
Independent & 0 & 15 & 20 \\
Energetic & 0 & 16 & 19 \\
Confident & 0 & 20 & 15 \\
Easy going & 1 & 21 & 13 \\
Stable & 0 & 22 & 13 \\
Normal & 0 & 22 & 13 \\
Enthusiastic & 1 & 23 & 11 \\
Hopeful & 3 & 24 & 8 \\
Cooperative & 1 & 25 & 9 \\
Caring & 0 & 27 & 8 \\
Attractive & 1 & 29 & 5 \\
Down to earth & 0 & 29 & 6 \\
Friendly & 0 & 29 & 6 \\
Tidy appearance & 0 & 32 & 3 \\
& & & \\
"Negative" personality characteristics & & \\
Bored & 18 & 16 & 1 \\
Unhappy & 17 & 16 & 2 \\
Worried & 16 & 15 & 4 \\
Frustrated & 16 & 17 & 2 \\
Dissatisfied & 15 & 20 & 0 \\
Irritable & 14 & 19 & 2 \\
Unreasonable & 12 & 20 & 3 \\
Quick tempered & 9 & 24 & 2 \\
Aggressive & 7 & 25 & 3 \\
Withdrawn & 7 & 27 & 0 \\
Useless & 5 & 30 & 0 \\
Worthless & 5 & & \\
\hline Nity & & \\
\hline
\end{tabular}

Values are numbers of patients.

result of brain damage-and also carer factors such as their own distress, personality, and change in life circumstances. It remains uncertain to what degree the observed major personality and behavioural change seen acutely after a stroke, such as emotionalism, correlates with later carer perceived personality change.

Attempting to measure "personality change" as described by the carer is difficult, partly because it may mean different things to different people, but also because it is an inherently heterogeneous problem. Although studies have been carried out in patients with conditions such as dementia, ${ }^{15}$ subarachnoid haemorrhage, ${ }^{16}$ and head injury, ${ }^{6}$ there has been a marked neglect of this area in ischaemic stroke research. ${ }^{1}$

We are aware of no other similar study based on carer ratings of personality before and after predominantly ischaemic stroke. Personality change $(42 \%)$ and distressing behaviour (35\%) were reported in one study following stroke, ${ }^{17}$ and another reported an increase in six unspecified

Table 3 Carers' rating of personality change according to the Oxford community stroke project classification

\begin{tabular}{lll}
\hline & $\mathbf{n}$ & $\begin{array}{l}\text { Mean change in } \\
\text { score* }\end{array}$ \\
\hline TACS & 4 & $\mathbf{C l})$ \\
POCS & 7 & $1.0(-0.2$ to 2.2$)$ \\
PACS & 10 & $0.8(0.1$ to 1.6$)$ \\
LACS & 14 & $0.6(0.3$ to 1.0$)$ \\
& & $0.25(0.1$ to 0.4$)$
\end{tabular}

*A score of 1 equals a change for the worse from one response to the next worse (for example, from "neither agree nor disagree" to "agree")

$\mathrm{Cl}$, confidence interval; LACS, lacunar stroke; PACS, partial anterior circulation stroke; POCS, posterior circulation stroke; TACS, total anterior circulation stroke. 
negative personality characteristics and a decrease in two positive personality characteristics after stroke. ${ }^{18}$ Several other studies have reported on personality change from cross sectional reports lacking any assessment of pre-stroke personality. Anderson et a ${ }^{19}$ reported a range of abnormal behaviours at one year post-stroke, such as withdrawal $(49 \%)$, irritability (49\%), odd ideas (35\%), unpredictability $(35 \%)$, rudeness $(23 \%)$, and odd behaviour (17\%). Similarly, Bogousslavsky reported various behaviours in a cohort of over 300 stroke patients, ${ }^{20}$ including sadness $(72 \%)$, disinhibition $(56 \%)$, lack of adaptation $(44 \%)$, environmental withdrawal $(40 \%)$, crying $(27 \%)$, passivity $(24 \%)$, and aggressiveness (11\%). Most recently, Martin et al applied the European brain injury questionnaire to 214 patients after stroke and to 195 of their carers ${ }^{21}$ and reported that there were significant differences between carer and patient ratings in several items, including: "being unsure what to do in dangerous situations", "thinking only of yourself", "everything is an effort", and "failing to notice other people's moods". In the only study involving patient ratings of personality change that we are aware of, 26 patients with stroke reported being less interested, independent, in control, and satisfied after their stroke. ${ }^{22}$ They still saw themselves as friendly, calm, caring, hopeful, and talkative.

Our finding that carer emotional distress was more strongly associated with carer rated personality change than patient self rated emotional distress is open to several different interpretations. Perhaps the carer is more distressed by a personality change of which the patient is less aware; this could be viewed as a form of "emotional anosagnosia" and would be supported by the discrepancy between interview rated and self rated measures of emotional distress. Alternatively, carers who are prone to emotional distress themselves may tend to perceive greater personality change. For example, the carer of one patient with stroke wrote: "My husband is not very interested in things going on around him and although I get tired doing things around the house he just sits and watches me struggle along. I have to ask for his help at times, although he will do things if I ask him". This quote illustrates some of the difficulties in this area. Is the primary problem in this case apathetic personality change in the patient, tiredness and emotional disorder in a carer having to look after a disabled person, or a combination of both?

Han and Haley ${ }^{23}$ examined 20 published studies of carer distress and burden and we have searched for subsequent studies. Three suggested that "abnormal behaviour" in the patient is a predictor of carer depression. ${ }^{19}{ }^{24} 25$ There is a less clear relation between carer and patient depression, with one negative $^{26}$ and two positive studies. ${ }^{2427} 28$ Surprisingly, although four studies have found an association between carer depression $^{18}{ }^{28-30}$ and physical disability in the patient, six did not find a relation. ${ }^{19}{ }^{24} 31-34$ A subsequent report has suggested that carer depression is related to perceived patient disability rather than to objective disability. ${ }^{35}$ Taken together, these studies emphasise the greater importance of behavioural and emotional variables in the patient compared with physical variables in determining caregiver burden.

\section{Limitations}

The study is small and was intended to be exploratory. Because of the multiple tests, some of the statistically significant results could have occurred by chance. The measure of personality change used has good face validity but its psychometric properties have not been examined. Thus associations between these measure other variables should also be viewed as only exploratory. Finally we report only associations, and the direction of causality between these cannot be determined.
Although better known measures such as the NEO and Eysenck personality inventories have been applied cross sectionally to stroke patients, ${ }^{36}$ it is not clear how valid these instruments are in patients with a high incidence of emotional disorder ${ }^{37}$ or brain damage, or how informative the scores from these instruments are in understanding a complex phenomenon such as personality change.

In our study, words commonly used to describe personality change were derived from previous studies of patients with head injury and from our own clinical experience. That many of these words could also describe emotional distress (for example, "worried") or disability ("independent") highlights the multifaceted nature of personality change as described by carers. Notably, we found little overall change in aggressiveness or quick temperedness in this study. ${ }^{314}$ We might have expected more change in these items if the patients had suffered more extensive strokes.

We found a positive relation between residual physical disability and personality change using the Nottingham EADL score but not the Barthel index. The lack of correlation with Barthel index may have reflected the known ceiling effect of this measure in groups such as this with milder stroke, or it could have reflected the small size of our sample. The relation between disability and personality change may to some extent be confounded by emotional disorder, which itself is correlated with disability regardless of the underlying diagnosis. ${ }^{38}$

\section{Conclusions}

If we are to offer useful interventions for the problem of personality change as reported by carers of stroke patients we need to understand more about its nature and its associations. This may mean attempting to study subtle changes such as apathy, as well as more striking phenomena such as emotionalism. Emotional disorder, disability, and cognitive impairment are likely to be important components of personality change. However, it also appears to be particularly important to consider the role of the carer factors such as emotional distress as potentially magnifying perceptions of personality change. A larger study, currently in progress, with standardised interview based methods may help disentangle further the nature of personality change after stroke.

\section{ACKNOWLEDGEMENTS}

We are grateful to the Medical Research Council (UK) and Chest Heart and Stroke Scotland for funding this work.

\section{Authors' affiliations \\ J Stone, K Haga, M Dennis, Division of Clinical Neurosciences, School of Molecular and Clinical Medicine, University of Edinburgh, Western General Hospital, Edinburgh, UK \\ E Townend, Nursing Research Initiative for Scotland, Glasgow Caledonian University, Glasgow, UK \\ M Sharpe, Division of Psychiatry, School of Molecular and Clinical Medicine, University of Edinburgh, Royal Edinburgh Hospital, Edinburgh J Kwan, University Department of Geriatric Medicine, Southampton General Hospital, Southampton, UK \\ Competing interests: none declared}

\section{REFERENCES}

1 Johnson GA. Research into psychiatric disorder after stroke: the need for further studies. Aust NZ J Psychiatry 1991;25:358-70.

2 House A, Dennis M, Molyneux A, et al. Emotionalism after stroke. BM 1989;298:991-4.

3 Kim JS, Choi S, Kwon SU, et al. Inability to control anger or aggression after stroke. Neurology 2002;58: 1106-8.

4 Hodkinson HM. Evaluation of a mental test score for assessment of mental impairment in the elderly. Age Ageing 1972;1:233-8.

5 Tyerman A, Humphrey M. Changes in self-concept following severe head injury. Int J Rehabil Res 1984;7:11-23. 
6 Brooks DN, McKinlay W. Personality and behavioural change after severe blunt head injury - a relative's view. J Neurol Neurosurg Psychiatry 1983;46:336-44.

7 Zigmond AS, Snaith RP. The hospital anxiety and depression scale. Acta Psychiatr Scand 1983;67:361-70.

8 Bjelland I, Dahl AA, Haug T, et al. The validity of the hospital anxiety and depression scale. An updated literature review. J Psychosom Res 2002;52:69-77

9 Brott T, Adams HP, Olinger CP, et al. Measurements of acute cerebral infarction: a clinical examination scale. Stroke 1989;20:864-70.

10 Bamford J, Sandercock P, Dennis M, et al. Classification and natural history of clinically identifiable subtypes of cerebral infarction. Lancet 1991;337:1521-6.

11 Mahoney FI, Barthel D. Functional evaluation: the Barthel Index. Maryland State Med J 1965;14:56-61.

12 Nouri FM, Lincoln NB. An extended activities of daily living scale for stroke patients. Clin Rehabil 1987;1:301-5.

13 First MB, Spitzer RL, Gibbon M, et al. Structured clinical interview for DSM-IV$T R$ axis I disorders, research version, patient edition (SCID-I/P). New York: Biometrics Research, New York State Psychiatric Institute, 2001.

14 Paradiso S, Robinson RG, Arndt S. Self-reported aggressive behavior in patients with stroke. J Nerv Ment Dis 1996;184:746-53.

15 Dawson DV, Welsh-Bohmer KA, Siegler IC. Premorbid personality predicts level of rated personality change in patients with Alzheimer disease. Alzheimer Dis Assoc Disord 2000;14:11-19.

16 Storey PB. Brain damage and personality change after subarachnoid haemorrhage. Br J Psychiatry 1970;1 17:129-42.

17 Bugge C, Alexander H, Hagen S. Patient, caregiver, and service factors that affect caregiver strain. Stroke 1999:30:1517-23.

18 Schulz R, Tompkins CA, Rau MT. A longitudinal study of the psychosocial impact of stroke on primary support persons. Psychol Aging 1988;3:131-41

19 Anderson CS, Linto J, Stewart-Wynne EG. A population-based assessment of the impact and burden of caregiving for long-term stroke survivors. Stroke 1995;26:843-9.

20 Bogousslavsky J. William Feinberg lecture 2002: Emotions, mood, and behavior after stroke. Stroke 2003;34:1046-50.

21 Martin C, Dellatolas G, Viguier D, et al. Subjective experience after stroke. Appl Neuropsychol 2002;9:148-58.

22 Ellis-Hill CS, Horn S. Change in identity and self-concept: a new theoretical approach to recovery following a stroke. Clin Rehabil 2000;14:279-87.
23 Han B, Haley WE. Family caregiving for patients with stroke. Review and analysis. Stroke 1999;30:1478-85.

24 Draper BM, Poulos CJ, Cole AM, et al. A comparison of caregivers for elderly stroke and dementia victims. J Am Geriatr Soc 1992:40:896-901.

25 Kinney JM, Stephens M, Franks MM, et al. Stress and satisfactions of family caregivers to older stroke patients. J Appl Gerontol 1995; 14:3-21.

26 Thompson SC, Sobolew-Shubin A, Graham MA, et al. Psychosocial adjustment following a stroke. Soc Sci Med 1989;28:239-47.

27 Carnwath TC, Johnson DA. Psychiatric morbidity among spouses of patients with stroke. BMJ 1987;294:409-11.

28 Wade DT, Legh-Smith J, Hewer RL. Effects of living with and looking after survivors of a stroke. BMJ 1986;293:418-20.

29 Jones AL, Charlesworth JF, Hendra TJ. Patient mood and carer strain during stroke rehabilitation in the community following early hospital discharge. Disabil Rehabil 2000;22:490-4.

30 Dennis $\mathrm{M}, \mathrm{O}^{\prime}$ Rourke $\mathrm{S}$, Lewis $\mathrm{S}$, et al. A quantitative study of the emotional outcome of people caring for stroke survivors. Stroke 1998;29:1867-72.

31 Kotila M, Numminen H, Waltimo O, et al. Depression after stroke: results of the FINNSTROKE Study. Stroke 1998;29:368-72.

32 Thommessen B, Wyller TB, Bautz-Holter E, et al. Acute phase predictors of subsequent psychosocial burden in carers of elderly stroke patients. Cerebrovasc Dis 2001;11:201-6.

33 Forsberg-Warleby G, Moller A, Blomstrand C. Spouses of first-ever stroke patients: psychological well-being in the first phase after stroke. Stroke 2001;32:1646-51.

34 Macnamara SE, Gummow $\sqcup$, Goka R, et al. Caregiver strain: need for late poststroke intervention. Rehabil Psychol 1990;35:71-7.

35 Kitze K, von Cramon DY, Wilz G. The emotional burden in caregiving relatives of stroke patients. Rehabilitation (Stuttg) 2002:41:401-6.

36 Aben I, Denollet J, Lousberg R, et al. Personality and vulnerability to depression in stroke patients: a 1 -year prospective follow-up study. Stroke 2002;33:2391-5

37 Farmer A, Redman K, Harris T, et al. Neuroticism, extraversion, life events and depression. The Cardiff Depression Study. Br J Psychiatry 2002;181:118-22.

38 Carson AJ, Ringbauer B, MacKenzie L, et al. Neurological disease, emotional disorder and disability: they are related. A study of 300 consecutive new referrals to a neurology outpatient department. I Neurol Neurosurg Psychiatry 2000;68:202-6. 